\title{
REFINE (Rapid Feedback for quality Improvement in Neonatal rEsuscitation): an observational study of neonatal resuscitation training and practice in a tertiary hospital in Nepal
}

Rejina Gurung ${ }^{1}$ (D) Abhishek Gurung ${ }^{1}$ (D) Omkar Basnet ${ }^{1}$, Joar Eilevstjønn², Helge Myklebust ${ }^{2}$, Sakina Girnary²,

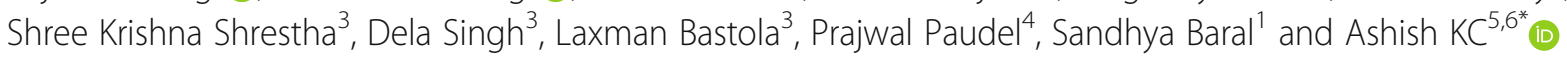

\begin{abstract}
Background: Simulation-based training in neonatal resuscitation is more effective when reinforced by both practice and continuous improvement processes. We aim to evaluate the effectiveness of a quality improvement program combined with an innovative provider feedback device on neonatal resuscitation practice and outcomes in a public referral hospital of Nepal.

Methods: A pre- and post-intervention study will be implemented in Pokhara Academy of Health Sciences, a hospital with 8610 deliveries per year. The intervention package will include simulation-based training (Helping Babies Breathe) enhanced with a real-time feedback system (the NeoBeat newborn heart rate meter with the NeoNatalie Live manikin and upright newborn bag-mask with PEEP) accompanied by a quality improvement process. An independent research team will collect perinatal data and conduct stakeholder interviews.
\end{abstract}

Discussion: This study will provide further information on the efficiency of neonatal resuscitation training and implementation in the context of new technologies and quality improvement processes.

Trial registration: https://doi.org/10.1186/ISRCTN18148368, date of registration-31 July 2018

Keywords: Newborn, Newborn resuscitation, REFINE, Helping babies breathe

\section{Background}

Worldwide, approximately 10 million newborns every year require assistance to breathe after birth. Studies show that timely and effective ventilation of these babies can significantly improve newborn survival. However, insufficient number of providers trained in newborn

\footnotetext{
* Correspondence: aaashis7@yahoo.com

${ }^{5}$ Society of Public Health Physician Nepal, Kathmandu, Nepal

${ }^{6}$ Department of Women's and Children's Health, Uppsala University, Dag Hammarskjölds väg 14B, 1 tr, 75237 Uppsala, Sweden

Full list of author information is available at the end of the article
}

resuscitation and a lack of clinical tools remain significant barriers [1-3]. The American Academy of Pediatrics (AAP) and their partners developed Helping Babies Breathe (HBB), a simulation-based curriculum, to train and equip healthcare providers to evaluate and support breathing at birth [4].

However, in resource-constrained environments like Nepal, there are several challenges to neonatal resuscitation training and implementation, including lack of time, equipment and resources [5]. Singhal et al., while developing an education program for newborn resuscitation

(C) The Author(s). 2020 Open Access This article is licensed under a Creative Commons Attribution 4.0 International License, which permits use, sharing, adaptation, distribution and reproduction in any medium or format, as long as you give appropriate credit to the original author(s) and the source, provide a link to the Creative Commons licence, and indicate if changes were made. The images or other third party material in this article are included in the article's Creative Commons licence, unless indicated otherwise in a credit line to the material. If material is not included in the article's Creative Commons licence and your intended use is not permitted by statutory regulation or exceeds the permitted use, you will need to obtain permission directly from the copyright holder. To view a copy of this licence, visit http://creativecommons.org/licenses/by/4.0/ The Creative Commons Public Domain Dedication waiver (http://creativecommons.org/publicdomain/zero/1.0/) applies to the data made available in this article, unless otherwise stated in a credit line to the data. 
in resource-constrained settings identified that additional training, education and guidance are necessary for improve retention and assimilation of resuscitation skills in clinical practice [6].

Simulation-based training has been used increasingly to help health workers convert knowledge and skills into practice $[7,8]$. Simulations help workers combine and reinforce their academic, intellectual, practical and interactive skills [9]. However, not much is known about the translation of training into clinical practice [10]. Also, health workers in poorly resourced settings may be unfamiliar with simulation-based training or even how to meet their training needs [11]. We believe that regular simulation-based practice in the form of drills will help them to translate their knowledge and skills into practice.

The Rapid Feedback for quality Improvement in Neonatal rEsuscitation (REFINE) study aims to improve the resuscitation skills of health workers using HBB training enhanced with a real-time feedback system (the NeoBeat newborn heart rate meter with the NeoNatalie Live manikin and upright newborn bag-mask with PEEP). The goal is to improve clinical performance and therefore newborn outcomes, monitored and reinforced using a quality improvement process.

\section{Methods/design}

\section{Aim}

The aim of this study is to evaluate the effect of an educational and quality improvement package on intrapartumrelated mortality, health workers' performance in newborn resuscitation, and stakeholder perceptions.

\section{Study design}

This is a pre- and post-intervention observational study. The pre-intervention period July 2017 - September 2018 will be taken as baseline period. The intervention period will be October 2018 - December 2020.

\section{Study setting}

The study will be conducted in the delivery unit at Pokhara Academy of Health Sciences (PoAHS), Pokhara. The hospital has 400 beds and 240 health workers. There is a delivery area for normal deliveries and an operation theatre for Caesarean-sections. The total annual delivery rate was 8610 in 2018, the stillbirth rate is 14 per 1000 total births with a neonatal mortality rate of 19 per 1000 live births.

\section{Study participants}

Study participants include health care providers and babies born in the hospitals. All the health care providers working in the labour room are eligible to the study. During the orientation to the health care providers on the quality improvement project, a group consent will be taken on the observation of health care provider's simulated practice in neonatalie live and clinical practice. Women with gestational age equal to or more than 22 weeks with a fetal heart sound admitted in the labour room for delivery will be approached for enrollment in the study. Women who consent to get enrolled will be included in the study.

\section{Data collection}

A team of data collectors, supervised by a research manager, will collect information on mortality outcomes and health worker's performance. The data collectors will extract information from the hospital records on sociodemographic characteristics of women enrolled and observe clinical resuscitation and immediate newborn practices. A standardized data collection protocol will be used to ensure consistency. Training will be provided to the data collectors on selection criteria, obtaining consent, clinical observation and data retrieval.

\section{Data retrieval}

Data will be extracted from the patient records and ward registers for the full study period.

\section{Clinical observations}

Clinical observations will be conducted to capture the clinical variables related to newborn resuscitation. A tablet-based observation tool has been developed and validated by Laerdal Global Health together with researchers from University of North Carolina and Kampala University. This novel application records newborn heart rate together with clinical variables.

\section{Process evaluation}

A qualitative data collection process will be implemented where an independent team will conduct indepth interviews and focus groups discussions with the health workers and relevant stakeholders (supplementary file 1). Furthermore, video filming will also be done in the end to document the implementation process and outputs.

\section{Outcome measure}

\section{Primary outcome measure}

Intrapartum stillbirth or death of newborn within $24 \mathrm{~h}$.

\section{Secondary outcome measures}

Health workers' performance (based on clinical observations):

Time to apply NeoBeat heart rate meter

Time to first spontaneous breath

Time of first inflation with bag-mask 
Ventilation with bag-mask in non-breathing babies at the rate of $40-60$ breaths per minute

Heart rate from the time of NeoBeat application until 10 min after birth

Apgar score at 1, 5 and 10 min after birth

Time of first spontaneous breath for non-breathing babies

\section{Interventions}

The REFINE intervention package will be implemented using four different approaches

1) A half a day workshop will be done to review the health worker's performance on neonatal resuscitation with hospital managers and head of department. The workshop participants will be oriented on the new technology implementation through quality approach;

2) One-day training on Helping Babies Breathe 2.0 version will be provided to health workers working in labour and delivery room;

3) A half of day orientation on the new technologies will be provided to the health workers. Health workers will be oriented on user guidance on neonatalie live, upright bag-mask with PEEP and Newborn Heart Rate Meter. Neonatalie live is a high fidelity simulator which provides real time feedback and debrief on the adequacy and ventilation practice in the simulator. Facilitation will be done to ensure that health workers practice neonatalie live before they resume their work in the labour room on a daily basis. Newborn heart rate meter measures neonatal heart rate and is placed in all babies who require resuscitation at birth. These technologies is co-developed by Laerdal Global Health.

4) A periodic meeting will be facilitated by the research team to discuss on the progress on implementation of the new technologies for improving neonatal resuscitation care using a PlanDo-Study-Act (PDSA) process. A performance dashboard on neonatal resuscitation will be used to conduct the PDSA meetings (Fig. 1).

\section{Sample size and power calculation}

Power calculation for the primary outcome is based on preliminary estimates of an intrapartum mortality of 20/ 1000 births and 8610 deliveries in the study hospitals per year. We estimate $20 \%$ reduction in the intrapartum mortality following implementation of the quality improvement package. With level of significance at $5 \%$ and statistical power at $80 \%$ to detect $20 \%$ reduction in intrapartum mortality we will require 10,023 birth. Intrapartum mortality is calculated as intrapartum stillbirth and first day mortality. Based on the current annual delivery rate, the duration of the intervention period will be 15 months.

\section{Data management}

For the purpose of ensuring high quality data collection, management and data security an independent data monitoring committee (IDMC) will be formed. All data will be saved on a server and backed up on a weekly basis. The project manager and the data manager will make spot checks monthly to verify records with the primary source of data. A quality control team from Laerdal Global Health will provide oversight on a regular basis to ensure quality of data collection and to avoid

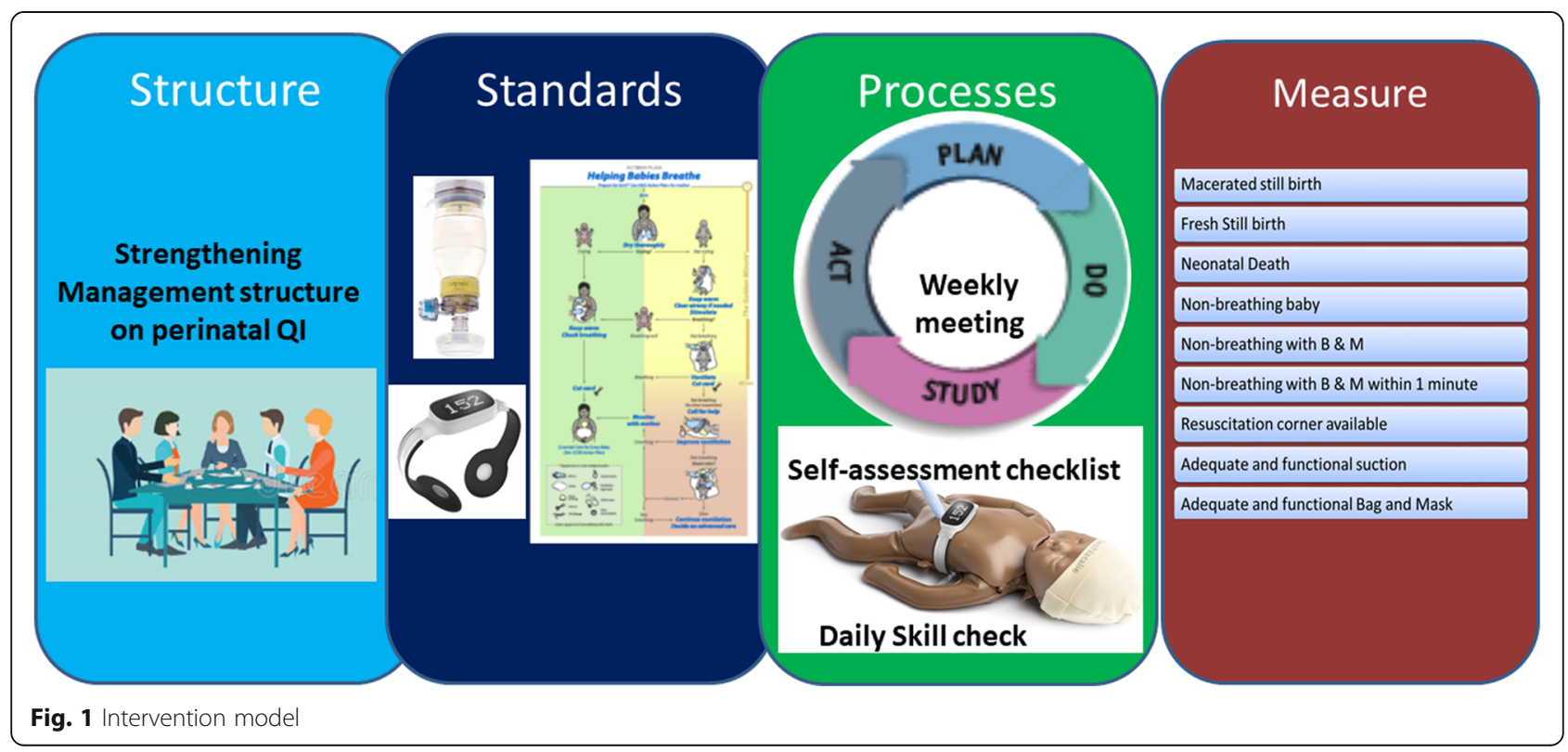


data loss. Procedures for data storage and handling will follow strict ethical review board and confidentiality rules.

\section{Data analysis}

Analysis of the intervention package effectiveness will be based on comparison between the baseline and end line intrapartum mortality and health worker performance (Fig. 2). Cross-sectional data gathered through the established surveillance system and clinical observations will produce a large dataset allowing for epidemiological analyses. The final report of this protocol will follow the general STrengthening the Reporting of OBservational studies in Epidemiology (STROBE) Statement and figure (supplementary file 2) [12]. Process evaluation will follow Medical Research Council (MRC) framework [13] for implementation and process level data. We have filled Standard Protocol Items: Recommendations for Interventional Trials (SPIRIT) checklist required for study protocol (supplementary file 3 ).

\section{Ethical consideration}

For this study, ethical approval (no. 87/2018) has been received from the national ethical review board, Nepal Health Research Council (NHRC). Ethical clearance will also be received from the Institutional Review Board (IRB) in the academy where the study will be conducted. Group consent will be taken from health workers to collect information on health worker's performance in simulated and clinical setting. Written informed consent will be taken from the pregnant women before clinical observations and confidentiality will be maintained. All ethical principles outlined in the World Medical Association (WMA) Declaration of Helsinki will be observed [14]. Authorship will follow Vancouver principles and all funding sources will be declared in publications.

\section{Discussion}

Helping Babies Breathe training has been successful in improving newborn outcomes [15, 16]. Previous study led by $\mathrm{KC}$ and colleagues has also shown that a quality improvement approach leads to improved adherence of

\begin{tabular}{|c|c|c|c|c|c|c|c|}
\hline \multirow[b]{4}{*}{ TIMEPOINT ${ }^{\star *}$} & \multicolumn{6}{|c|}{ STUDY PERIOD } & \multirow{3}{*}{ Close-out } \\
\hline & \multirow{3}{*}{$\begin{array}{l}\text { Enrolment } \\
2019-2020\end{array}$} & \multirow{3}{*}{$\begin{array}{l}\text { Allocation } \\
2019-2020\end{array}$} & \multicolumn{4}{|c|}{ Post-allocation } & \\
\hline & & & \multicolumn{2}{|c|}{2019} & \multicolumn{2}{|c|}{2020} & \\
\hline & & & $\begin{array}{l}\text { Q1: } \\
Q^{\prime \prime}\end{array}$ & $\begin{array}{l}\text { Q3- } \\
\text { Q4 }\end{array}$ & $\begin{array}{l}\text { Q1: } \\
Q^{\prime \prime}\end{array}$ & $\begin{array}{l}\text { Q3- } \\
\text { Q4 }\end{array}$ & $\begin{array}{l}Q 1-Q 2 \\
2021\end{array}$ \\
\hline \multicolumn{8}{|l|}{ ENROLMENT: } \\
\hline Eligibility screen & $\mathrm{X}$ & $\mathrm{X}$ & $\mathrm{X}$ & $\mathrm{X}$ & $\mathrm{X}$ & $\mathrm{X}$ & $\mathrm{X}$ \\
\hline Informed consent & $\mathrm{X}$ & $\mathrm{X}$ & $\mathrm{X}$ & $\mathrm{X}$ & $\mathrm{X}$ & $\mathrm{X}$ & $\mathrm{X}$ \\
\hline Allocation & & $\mathrm{X}$ & $\mathrm{X}$ & $\mathrm{X}$ & $\mathrm{X}$ & $\mathrm{X}$ & $\mathrm{X}$ \\
\hline \multicolumn{8}{|l|}{ INTERVENTIONS: } \\
\hline \multicolumn{8}{|l|}{$\begin{array}{r}\text { REFINE quality improvement } \\
\text { package }\end{array}$} \\
\hline \multicolumn{8}{|l|}{ REFINE technology } \\
\hline \multicolumn{8}{|l|}{ ASSESSMENTS: } \\
\hline $\begin{array}{r}\text { Intrapartum stillbirth and death } \\
\text { of newborn within } 24 \text { hours }\end{array}$ & $\mathrm{X}$ & $\mathrm{X}$ & $\mathrm{X}$ & $\mathrm{X}$ & $\mathrm{X}$ & $\mathrm{X}$ & $\mathrm{X}$ \\
\hline $\begin{array}{r}\text { Time to apply NeoBeat heart } \\
\text { rate meter }\end{array}$ & $\mathrm{X}$ & $\mathrm{X}$ & $\mathrm{X}$ & $\mathrm{X}$ & $\mathrm{X}$ & $\mathrm{X}$ & $\mathrm{X}$ \\
\hline $\begin{array}{r}\text { Time to first spontaneous } \\
\text { breath }\end{array}$ & $\mathrm{X}$ & $\mathrm{X}$ & $\mathrm{X}$ & $\mathrm{X}$ & $\mathrm{X}$ & $\mathrm{X}$ & $\mathrm{X}$ \\
\hline $\begin{array}{r}\text { Time of first inflation with bag- } \\
\text { mask }\end{array}$ & $\mathrm{X}$ & $\mathrm{X}$ & $\mathrm{X}$ & $\mathrm{X}$ & $\mathrm{X}$ & $\mathrm{X}$ & $\mathrm{X}$ \\
\hline $\begin{array}{r}\text { Ventilation with bag-mask in } \\
\text { non-breathing babies at the } \\
\text { rate of } 40-60 \text { breaths per } \\
\text { minute }\end{array}$ & $\mathrm{X}$ & $\mathrm{X}$ & $\mathrm{X}$ & $\mathrm{X}$ & $\mathrm{X}$ & $\mathrm{X}$ & $\mathrm{X}$ \\
\hline $\begin{array}{r}\text { Heart rate from the time of } \\
\text { NeoBeat application until } 10 \\
\text { minutes after birth }\end{array}$ & $\mathrm{X}$ & $\mathrm{X}$ & $\mathrm{X}$ & $\mathrm{X}$ & $\mathrm{X}$ & $\mathrm{X}$ & $\mathrm{X}$ \\
\hline $\begin{array}{r}\text { Apgar score at } 1,5 \text { and } 10 \\
\text { minutes after birth }\end{array}$ & $\mathrm{X}$ & $\mathrm{X}$ & $\mathrm{X}$ & $\mathrm{X}$ & $\mathrm{X}$ & $\mathrm{X}$ & $\mathrm{X}$ \\
\hline $\begin{array}{l}\text { Time of first spontaneous } \\
\text { breath for non-breathing babies }\end{array}$ & $\mathrm{X}$ & $\mathrm{X}$ & $\mathrm{X}$ & $\mathrm{X}$ & $\mathrm{X}$ & $\mathrm{X}$ & $\mathrm{X}$ \\
\hline
\end{tabular}

Fig. 2 SPIRIT timeline 
the health workers in practicing neonatal resuscitation protocol. It also led to decreased intrapartum stillbirth and newborn mortality $[17,18]$. Evidence has shown that improved newborn resuscitation knowledge and skills are necessary to decrease birth asphyxia related newborn mortalities [19]. Furthermore, it is important to understand that not all non-breathing babies require bag and mask ventilation and may breathe through simple stimulation or airway clearance [20]. These observations are vital to understanding the process and providing care.

This research team has been involved in a large-scale QI intervention in 12 public hospitals of Nepal, which aimed to improve adherence of health workers for newborn interventions aimed at improving newborn survival [21]. The current study will build upon our experience and aims to improve health workers' capacity through further enhancements in the both training and daily practice by introducing novel resuscitation technologies. A QI approach should identify bottlenecks and help overcome barriers. The study will also evaluate the use of new technologies. The clinical, QI, and qualitative results will guide future newborn policies and protocols and related resource investments.

One of the limitations of the study can be unforseen short-term impact of the training and drills on clinical practice. This study is built upon previous and ongoing QI interventions, there is a likelihood of contamination resulting in improved outcomes. Further, the technology such as neonatalie live, neobeat and upright bag-andmask are provided by Laerdal Global Health, we will manage the data and results anonymously maintain research integrity. Finally, if there is evidence of improved outcomes, we plan to scale-up the interventions with the goal of sustainability in the medium and long term.

\section{Supplementary Information}

The online version contains supplementary material available at https://doi. org/10.1186/s12884-020-03456-z.

Additional file 1. SPIRINT checklist filled.

Additional file 2. STROBE flow figure.

Additional file 3. Indepth interview questionnaires.

\begin{abstract}
Abbreviations
AAP: American Academy of Pediatrics; ENAP: Every Newborn Action Plan; HBB: Helping Babies Breathe; IDMC: Independent Data Monitoring Committee; ILCOR: International Liaison on Resuscitation; IRB: Institutional Review Board; NePeriQIP: Nepal Perinatal Quality Improvement Project; NHRC: Nepal Health Research Council; PoAHS: Pokhara Academy of Health Sciences; REFINE: Rapid Feedback for quality Improvement Neonatal rEsuscitation; SDG: Sustainable Development Goal; STROBE: STrengthening the Reporting of OBservational studies in Epidemiology; Ql: Quality improvement; WMA: World Medical Association
\end{abstract}

\section{Acknowledgements}

We would like to thank the Laerdal Global Health, Golden Community and Pokhara Academy of Health Sciences team for the design input.

\section{Authors' contributions}

RG conceptualized the study. AG and AKC wrote the first draft. OB, JE, HM, $S G, S K S, D S, L B, P P$ and $S B$ provided the input in the design of the study and manuscript. All authors reviewed and approved the final manuscript.

\section{Funding}

The study is partly being funded from Innovation Norway, Norwegian Research Council. Laerdal Global Health will provide equipment for the study. Additional funding will be applied to Laerdal Foundation for Acute Medicine. The funding agency will have no influence in the design and implementation of the study. Open Access funding provided by Uppsala University.

\section{Availability of data and materials}

Not applicable.

\section{Ethics approval and consent to participate}

For this study, ethical approval (no. 87/2018) has been received from the national ethical review board, Nepal Health Research Council (NHRC). Ethical clearance will also be received from the Institutional Review Board (IRB) in the Pokhara Academy of Health Sciences where the study will be conducted. Group consent was taken from the health workers on video recording and direct observation. Written informed consent will be taken from the pregnant women before clinical observations and confidentiality will be maintained.

\section{Consent for publication}

Not applicable.

\section{Competing interests}

The authors declare no any competing interests. Laerdal Global Health will provide equipment for the study and will play no role in the study design and implementation.

\section{Author details}

'Golden Community, Jawagal, Lalitpur, Nepal. ${ }^{2}$ Laerdal Medicine/Laerdal Global Health, Stavanger, Norway. ${ }^{3}$ Pokhara Academy of Health Sciences, Pokhara, Nepal. ${ }^{4}$ Paropakar Maternity and Women's Hospital, Kathmandu, Nepal. ${ }^{5}$ Society of Public Health Physician Nepal, Kathmandu, Nepal. ${ }^{6}$ Department of Women's and Children's Health, Uppsala University, Dag Hammarskjölds väg 14B, 1 tr, 75237 Uppsala, Sweden.

Received: 12 September 2019 Accepted: 25 November 2020 Published online: 03 December 2020

\section{References}

1. Bhutta ZA, Das JK, Bahl R, Lawn JE, Salam RA, Paul VK, et al. Can available interventions end preventable deaths in mothers, newborn babies, and stillbirths, and at what cost? Lancet. 2014;384:347-70.

2. Wall SN, Lee AC, Niermeyer S, English M, Keenan WJ, Carlo W, et al. Neonatal resuscitation in low-resource settings: what, who, and how to overcome challenges to scale up? Int J Gynecol Obstet. 2010;107(Suppl 1): S47-64.

3. Lee AC, Cousens S, Wall SN, Niermeyer S, Darmstadt GL, Carlo WA, et al. Neonatal resuscitation and immediate newborn assessment and stimulation for the prevention of neonatal deaths: a systematic review, meta-analysis and Delphi estimation of mortality effect. BMC Public Health. 2011;11(Suppl 3):S12.

4. Callister LC. The golden minute: helping babies breathe. MCN Am J Matern Nurs. 2014;39:271.

5. Bang A, Patel A, Bellad R, Gisore P, Goudar SS, Esamai F, et al. Helping babies breathe (HBB) training: what happens to knowledge and skills over time? BMC Pregnancy Childbirth. 2016;16(1):364.

6. Singhal N, Lockyer J, Fidler H, Keenan W, Little G, Bucher S, et al. Helping babies breathe: global neonatal resuscitation program development and formative educational evaluation. Resuscitation. 2012;83:90-6.

7. Cooper S, Cant R, Porter J, Bogossian F, McKenna L, Brady S, et al. Simulation based learning in midwifery education: a systematic review. Women Birth. 2012;25:64-78. 
8. Dawe SR, Pena GN, Windsor JA, Broeders JAJL, Cregan PC, Hewett PJ, et al. Systematic review of skills transfer after surgical simulation-based training. Br J Surg. 2014;101:1063-76.

9. Ersdal HL, Vossius C, Bayo E, Mduma E, Perlman J, Lippert A, et al. A one-day "helping babies breathe" course improves simulated performance but not clinical management of neonates. Resuscitation. 2013;84:1422-7.

10. Mduma E, Ersdal H, Svensen E, Kidanto H, Auestad B, Perlman J. Frequent brief on-site simulation training and reduction in 24-h neonatal mortality-an educational intervention study. Resuscitation. 2015;93:1-7.

11. Rowe AK, De Savigny D, Lanata CF, Victora CG. How can we achieve and maintain high-quality performance of health workers in low-resource settings? Lancet. 2005;366:1026-35.

12. Vandenbroucke JP, von Elm E, Altman DG, Gøtzsche PC, Mulrow CD, Pocock $\mathrm{SJ}$, et al. Strengthening the reporting of observational studies in epidemiology (STROBE): explanation and elaboration. Int J Surg. 2014;12: 1500-24. https://doi.org/10.1016/j.jijsu.2014.07.014.

13. Moore GF, Audrey S, Barker M, Bond L, Bonell C, Hardeman W, et al. Process evaluation of complex interventions: Medical Research Council guidance. BMJ. 2015;350:1-7.

14. World Medical Association. Declaration of Helsinki. 1974.

15. Goudar SS, Somannavar MS, Clark R, Lockyer JM, Revankar AP, Fidler HM, et al. Stillbirth and newborn mortality in India after helping babies breathe training. Pediatrics. 2013;131:e344-52. https://doi.org/10.1542/peds.2012-2112.

16. Msemo G, Massawe A, Mmbando D, Rusibamayila N, Manji K, Kidanto HL, et al. Newborn mortality and fresh stillbirth rates in Tanzania after helping babies breathe training. Pediatrics. 2013;131:e353-60. https://doi.org/10. 1542/peds.2012-1795.

17. KC A, Wrammert J, Clark RB, Ewald U, Vitrakoti R, Chaudhary P, et al. Reducing perinatal mortality in Nepal using helping babies breathe. Pediatrics. 2016;137:e20150117. https://doi.org/10.1542/peds.2015-0117.

18. KC A, Wrammert J, Nelin V, Clark RB, Ewald U, Peterson S, et al. Evaluation of helping babies breathe quality improvement cycle (HBB-QIC) on retention of neonatal resuscitation skills six months after training in Nepal. BMC Pediatr. 2017;17(1):103

19. Dol J, Campbell-Yeo M, Tomblin-Murphy G, Aston M, McMillan D, Richardson B. The impact of the helping babies survive program on neonatal outcomes and health provider skills: a systematic review protocol. JBI Database Syst Rev Implement Rep. 2017;15:1528-36.

20. Ersdal HL, Mduma E, Svensen E, Perlman JM. Early initiation of basic resuscitation interventions including face mask ventilation may reduce birth asphyxia related mortality in low-income countries. A prospective descriptive observational study. Resuscitation. 2012;83(7):869-73.

21. Kc A, Ewald U, Basnet O, Gurung A, Pyakuryal SN, Jha BK, Bergstrom A, Eriksson L, Paudel P, Karki S, et al. Effect of a scaled-up neonatal resuscitation quality improvement package on intrapartum-related mortality in Nepal: a stepped-wedge cluster randomized controlled trial. PLoS Med. 2019;16(9):e1002900.

\section{Publisher's Note}

Springer Nature remains neutral with regard to jurisdictional claims in published maps and institutional affiliations.

Ready to submit your research? Choose BMC and benefit from:

- fast, convenient online submission

- thorough peer review by experienced researchers in your field

- rapid publication on acceptance

- support for research data, including large and complex data types

- gold Open Access which fosters wider collaboration and increased citations

- maximum visibility for your research: over $100 \mathrm{M}$ website views per year

At $\mathrm{BMC}$, research is always in progress.

Learn more biomedcentral.com/submissions 